\title{
WLB in Zahlen 2015
}

\begin{tabular}{|c|c|}
\hline \multicolumn{2}{|l|}{ Gesamtbestand (Stand: 2.2.2016) } \\
\hline Medienbestand insgesamt & 5.968 .397 \\
\hline \multicolumn{2}{|l|}{ davon: } \\
\hline Buchmaterialien & 3.950 .475 \\
\hline Autographen & 180.531 \\
\hline Handschriften & 15.519 \\
\hline Inkunabeln & 7.091 \\
\hline Noten & 72.836 \\
\hline Karten & 155.130 \\
\hline Mikroformen & 479.458 \\
\hline AV-Materialien (Ton-, Bildträger) & 47.133 \\
\hline CD-ROMS & 26.273 \\
\hline Flugblätter & 160.803 \\
\hline Fotos & 580.345 \\
\hline Plakate & 39.931 \\
\hline Feldpostbriefe & 136.960 \\
\hline Porträts & 36.903 \\
\hline $\begin{array}{l}\text { Sonstiges davon: Varia 3.464, Disketten 3.391, Ortsansichten 8.312, Ansichtskarten 36.637, Ereignisdarstellungen 2.000, } \\
\text { Slg. Nicolai 22.000, Einblattmat./Sonstige 3.047, Nachlässe } 158\end{array}$ & 79.009 \\
\hline Bibeln (in 655 Sprachen) & 20.206 \\
\hline Lfd. geh. Zeitschriften u. Zeitungen (Abos) & 11.611 \\
\hline Angebot an elektronischen Zeitschriften & 24.422 \\
\hline Angebot an online-Datenbanken & 276 \\
\hline Angebot an E-Books & 26.600 \\
\hline Zugang 2015 & 58.166 \\
\hline Kauf & 26.132 \\
\hline Pflicht & 25.597 \\
\hline Tausch & 401 \\
\hline Geschenk & 6.036 \\
\hline \multicolumn{2}{|l|}{ Benutzung 2015} \\
\hline Öffnungstage & 291 \\
\hline Öffnungsstunden pro Woche & 64 \\
\hline Entleihungen insgesamt & 1.539 .136 \\
\hline Aktive Benutzer/innen & 29.614 \\
\hline Benutzerfälle in den Lesesälen & 224.021 \\
\hline Benutzerschulungen / Führungen (Stunden) & 387 \\
\hline Fernleihbestellungen (aktiv, pos. erledigt) & 38.535 \\
\hline Fernleihbestellungen (passiv, pos. erledigt) & 15.655 \\
\hline Personalstellen 2015 & 129 \\
\hline Kulturelle Veranstaltungen 2015 & 24 \\
\hline Ausstellungen & 8 \\
\hline Weitere Veranstaltungen & 16 \\
\hline
\end{tabular}

